\title{
Commentary: Measure twice, but cut early?
}

\section{Eugene J. Won, MD, and Louis H. Stein, MD, PhD}

The incidence of acute aortic syndromes has increased despite a rise in elective aortic operations. ${ }^{1}$ The size criteria for aortic intervention incorporates the understanding that structural integrity of the aorta deteriorates with increasing aortic diameter. This has led some to suggest that operating earlier for smaller aneurysms may reduce risk and help prevent emergency cases. ${ }^{1-3}$

Carlestål and colleagues ${ }^{4}$ report their experience with prophylactic ascending aortic replacement in asymptomatic patients with median ascending aortic or root diameter of $55 \mathrm{~mm}$. Immediate postoperative complications in this 262 -patient cohort were low $(0.76 \%$ mortality and $0.76 \%$ stroke within the first 30 days). No additional complications were reported up to 1 year. These data are longer term than what have been previously reported and further support the growing evidence that describes elective proximal aortic surgery within the realm of acceptable risk.

Given this improved surgical risk, the threshold to operate on a smaller aortic diameter may be lowered for a number of reasons. Aortic diameter correlates with the vessel's mechanical function. ${ }^{5}$ In their updated study of 3400 patients, the Yale Aortic Institute found the inflection point to be at $52.5 \mathrm{~mm} .^{3}$ Other studies have demonstrated that most patients presenting with type A dissection present with aortic diameters $<55 \mathrm{~mm} .{ }^{6,7}$ Family history, symptoms, and genetic profile have also been proposed as alternative indicators of increased risk that may warrant earlier intervention. $^{8}$

The timing of surgery is 1 issue, but there is also the issue of identifying those who would benefit from early

From the Department of Cardiothoracic Surgery, RWJBarnabas Health at Newark Beth Israel Medical Center, Newark, NJ.

Disclosures: The authors reported no conflicts of interest.

The Journal policy requires editors and reviewers to disclose conflicts of interest and to decline handling or reviewing manuscripts for which they may have a conflict of interest. The editors and reviewers of this article have no conflicts of interest.

Received for publication May 25, 2021; revisions received May 25, 2021; accepted for publication May 26, 2021; available ahead of print June 24, 2021.

Address for reprints: Louis H. Stein, MD, PhD, Department of Cardiothoracic Surgery, RWJBarnabas Health at Newark Beth Israel Medical Center, 201 Lyons

Ave, Suite G5, Newark, NJ 07112 (E-mail: Louis.stein@rwjbh.org).

JTCVS Open 2021;7:10-1

2666-2736

Copyright (C) 2021 The Author(s). Published by Elsevier Inc. on behalf of The American Association for Thoracic Surgery. This is an open access article under the CC BY-NC-ND license (http://creativecommons.org/licenses/by-nc-nd/4.0/).

https://doi.org/10.1016/j.xjon.2021.05.015

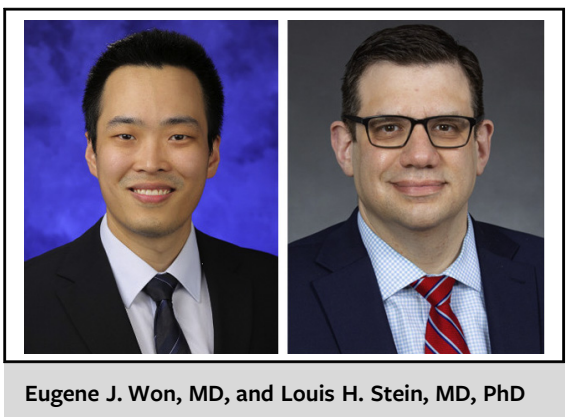

CENTRAL MESSAGE

Mortality and major complica-

tions were rare in prophylactic

proximal aortic operations for

asymptomatic patients with

ascending thoracic aortic

aneurysm.

intervention. What makes thoracic aortic disease most challenging is that patients are often asymptomatic and undiagnosed until dissection or rupture. Screening programs have been proposed and may benefit first- and second-degree relatives of patients with thoracic aortic disease, but the data are limited and younger relatives with familial disease may not be identified easily. ${ }^{9}$

Improved understanding of the natural history of aortic disease has shown us that predicting its progression will require a balanced understanding of genetics, phenotype, and symptoms as well as size. The role for early intervention will need to be clarified as data continue to accrue. The authors are to be congratulated for achieving excellent surgical results within a guideline-compliant cohort. These data provide reassurance that guideline-directed interventions can be performed safely.

\section{References}

1. Mullan CW, Mori M, Bin Mahmood SU, Yousef S, Mangi AA, Elefteriades JA, et al. Incidence and characteristics of hospitalization for proximal aortic surgery for acute syndromes and for aneurysms in the USA from 2005 to 2014. Eur J Cardiothorac Surg. 2020;58:583-9.

2. Gagne-Loranger M, Dumont E, Voisine P, Mohammadi S, Dagenais F. Natural history of 40-50 $\mathrm{mm}$ root/ascending aortic aneurysms in the current era of dedicated thoracic aortic clinics. Eur J Cardiothorac Surg. 2016;5:562-6.

3. Ziganshin BA, Zafar MA, Elefteriades JA. Descending threshold for ascending aortic aneurysmectomy: is it time for a "left-shift" in guidelines? J Thorac Cardiovasc Surg. 2019;157:37-42.

4. Carlestål E, Ezer M, Franco-Cereceda A, Olsson C. Proximal aortic repair in asymptomatic patients. J Thorac Cardiovasc Surg Open. 2021;7:1-9.

5. Koullias G, Modak R, Tranquilli M, Korkolis DP, Barash P, Elefteriades JA. Mechanical deterioration underlies malignant behavior of aneurysmal human ascending aorta. J Thorac Cardiovasc Surg. 2005;130:677-83. 
6. Rylski B, Blanke P, Beyersdorf F, Desai ND, Milewski RK, Siepe M, et al. How does the ascending aorta geometry change when it dissects? J Am Coll Cardiol. 2014;63:1311-9.

7. Tozzi P, Gunga Z, Niclauss L, Delay D, Roumy A, Pfister R, et al. Type A aortic dissection in aneurysms having modelled pre-dissection maximum diameter below $45 \mathrm{~mm}$ : should we implement current guidelines to improve the survival benefit of prophylactic surgery? Eur J Cardiothorac Surg. 2021;59:473-8.
8. Tanweer M, Zafar MA, Saeyeldin A, Gryaznov AA, Puddifant AJ, Erben Y, et al. "Getting beyond diameter": when to replace the aorta? J Vis Surg. 2018;4:124.

9. Mariscalco G, Debiec R, Elefteriades JA, Samani NJ, Murphy GJ. Systematic review of studies that have evaluated screening tests in relatives of patients affected by nonsyndromic thoracic aortic disease. J Am Heart Assoc. 2018;7: e009302. 